\title{
A RELAÇÃO COM O ENSINO DE ESTATÍSTICA DE PROFESSORES DOS ANOS INICIAIS DO ENSINO FUNDAMENTAL EM ESCOLAS PÚBLICAS E PRIVADAS DE UBERLÂNDIA
}

\author{
Márcia Lopes Vieira e Ailton Paulo de Oliveira Júnior \\ Instituto Federal do Triângulo Mineiro, Brasil \\ Universidade Federal do Triângulo Mineiro, Brasil \\ marcialopes@iftm.edu.br
}

O objetivo do trabalho foi o de pesquisar as atitudes e concepções de professores dos anos iniciais do Ensino Fundamental em relação ao ensino de Estatística em oito escolas de Uberlândia, Minas Gerais, Brasil. Com questões abertas identificaram-se as concepções dos professores por meio de análise de conteúdo de Laurence Bardin. E foi adaptada a Escala de Atitudes de Professores em relação à Estatística de Ailton Paulo de Oliveira Júnior para determinar atitudes desses professores em relação ao Ensino de Estatística. Considera-se que o posicionamento dos professores se define como de natureza essencialmente cognitiva. Considerando os resultados obtidos na análise da confiabilidade e validade da escala, esta apresenta propriedades psicométricas satisfatórias para medir o constructo "Positividade da Atitude em relação ao Ensino de Estatística”.

\section{INTRODUÇÃO}

Segundo Zabalza (1994), por meio das concepções dos professores, pode-se compreender o seu universo e suas ações. O autor ainda define que concepção é aquilo que o professor, em um dado momento, dá por deliberado e que orienta a sua ação, explícita e implicitamente.

Nessa vertente, pode-se comungar também com Ponte (1992) ao definir que as concepções têm natureza essencialmente cognitiva e que atuam como uma espécie de filtro, dando sentido às coisas ou atuando como bloqueador para novas situações, limitando a possibilidade de atuação e compreensão. Como elas estruturam o sentido que se atribui às coisas surge uma indagação: $\mathrm{O}$ sentido e a intencionalidade educativa são elementos importantes para repensar a prática pedagógica do professor?

Diante dessa questão é oportuno dialogar com os Parâmetros Curriculares Nacionais, Brasil (1997), quanto ao desenvolvimento do ensino da Matemática, pois este ressalta que é necessário que o professor tenha clareza de suas próprias concepções sobre a disciplina, uma vez que em sala de aula, as suas escolhas pedagógicas, os conteúdos de ensino e as formas de avaliação da aprendizagem estão intimamente ligados a tais concepções.

Ligadas às concepções, estão as atitudes, por exemplo, as expectativas e o entendimento que cada professor tem do que constitui o seu papel em uma dada situação. A atitude constitui-se em uma condição psicológica necessária para que o indivíduo realize uma tarefa com sucesso, possui um caráter cognitivo e afetivo com tendência para a ação (Moron e Brito, 2001).

Segundo Serra (2007) o tema "atitudes" tem sido alvo de muitos estudos por parte dos psicólogos sociais. Cresceu o número de artigos sobre mudança de atitude e dos seus efeitos na comunicação social, sendo notada a quantidade de publicações realizadas nesse setor durante a década de 50. Ainda hoje as atitudes continuam a ter um importante papel nos estudos em psicologia social.

Uma das definições adotadas nesta pesquisa foi a de Brito (1998), ou seja, que considera a atitude como a maneira de ver, de sentir e de reagir, própria de cada indivíduo, dirigida a objetos, eventos ou pessoas, que assume diferente direção e intensidade de acordo com as suas experiências.

Completando esta definição agregamos a definição de Rodrigues, Assmar e Jablonski, (2005) que diz que atitude é uma organização duradoura de crenças e cognições, em geral dotada de carga pró ou contra um objeto social definido, que predispõe a uma ação coerente com as cognições e afetos relativos a esse objeto.

Tendo em vista o tema e o problema de pesquisa levantada, o objetivo geral é pesquisar as concepções e atitudes de professores dos anos iniciais do Ensino Fundamental em relação ao ensino de Estatística em oito escolas da cidade de Uberlândia no Triângulo Mineiro.

In: M.A. Sorto (Ed.), Advances in statistics education: developments, experiences and assessments. Proceedings of the Satellite conference of the International Association for Statistical Education (IASE), July 2015, Rio de Janeiro, Brazil. 


\section{PROCEDIMENTOS METODOLÓGICOS}

O público alvo da pesquisa são cinquenta e cinco professores dos anos iniciais do Ensino Fundamental de escolas públicas e privadas de Uberlândia, Minas Gerais que lecionam conteúdos de Matemática, sendo 15 professores de duas escolas estaduais, 15 professores de três escolas privadas, 13 professores de duas escolas municipais e 12 professores de uma escola federal.

As escolas públicas da pesquisa foram selecionadas de acordo com o seu Índice de Desenvolvimento da Educação Básica - Ideb, criado em 2007, pelo Instituto Nacional de Estudos e Pesquisas Educacionais Anísio Teixeira (Inep), formulado para medir a qualidade do aprendizado nacional e estabelecer metas para a melhoria do ensino (Brasil, 2014). No tocante às escolas privadas a amostragem escolhida é diversificada, uma vez que utilizou como critérios o tipo de escola, ou seja, confessional ou particular.

Assim, através de um questionário com questões abertas pretendeu-se verificar a concepção deste grupo de professores em relação ao ensino de Estatística. A primeira pergunta $(\mathrm{O}$ que é Estatística para você?) pretendeu investigar como os professores definem a Estatística. A segunda questão (Em sua opinião como uma pessoa adquire conhecimento em Estatística?) como este grupo de professores acredita que o conhecimento estatístico é adquirido, com o objetivo de identificar suas concepções sobre o uso de estatísticas. A terceira pergunta (Como você trabalha os conteúdos estatísticos em suas aulas?), objetiva identificar como esses professores trabalham com conteúdo estatístico em suas salas de aula. A última pergunta (Como você incorpora situações do cotidiano em suas aulas de Estatística?) procurou a opinião do mesmo grupo sobre o papel da utilização de situações do cotidiano no ensino.

A metodologia de análise das questões abertas é feita através da análise de conteúdo de Bardin (2009), que é um conjunto de técnicas de análise de comunicação que utiliza procedimentos sistemáticos e objetivos de descrição do conteúdo das mensagens e os organiza em três fases: (1) Pré-Análise; (2) Exploração do material; (3) Tratamento dos resultados inferência e interpretação.

Além das questões acima descritas, foi adaptada a Escala de Atitudes de Professores em relação à Estatística - EAPE de Oliveira Júnior e Morais (2009) para determinar como os professores dos anos iniciais do Ensino Fundamental se relacionam com o Ensino de Estatística.

A escala de Avaliação das Atitudes dos Professores em relação à Estatística é do tipo Likert, com 4 níveis (Concordo Totalmente; Concordo Parcialmente; Discordo Parcialmente; Discordo Totalmente), com proposições positivas e negativas, composta por 35 itens. Os itens positivos têm a seguinte pontuação: discordo totalmente (1), discordo parcialmente (2), concordo parcialmente (3) e concordo totalmente (4); enquanto que os itens negativos invertem a pontuação para: discordo totalmente (4), discordo parcialmente (3), concordo parcialmente (2) e concordo totalmente (1). Assim, a soma das pontuações nas 35 proposições da escala de atitudes pode variar de 35 (trinta e cinco) a 140 (cento e quarenta), indo de atitudes extremamente negativas a atitudes extremamente positivas em relação à Estatística.

No processo de avaliação da validade e confiabilidade da escala utilizada consideramos uma Análise Fatorial Exploratória para a identificação de domínios conceituais e para a eliminação de questões pouco relacionadas entre si. Após o estabelecimento das questões e domínios contidos na escala foi realizada uma análise fatorial confirmatória com o propósito de se avaliar a validade de constructo da escala. O Alfa de Cronbach para as questões ligadas a escala bem como para as questões ligadas a cada domínio conceitual foi avaliado com o propósito de se investigar a confiabilidade da escala.

Foram utilizados recursos computacionais para a tabulação, apresentação e análise de dados, tais como Microsoft Excel, Word e software estatístico livre ou o Statistical Package for the Social Sciences - SPSS 19.0.

\section{RESULTADOS}

Para facilitar a apresentação dos relatos dos professores em relação as suas concepções no Ensino de Estatística utilizamos a seguinte caracterização: (1) professores de Escolas Estaduais (PEE) seguido do número de identificação do professor (por exemplo, PEE1); (2) professores de Escolas Municipais (PEM) seguido do número de identificação do professor (por exemplo, PEM2); (3) professores da Escola Federal (PEF) seguido do número de identificação do professor (por 
exemplo, PEF3); (4) professores de Escolas Privadas (PEP) seguido do número de identificação do professor (por exemplo, PEP4).

$\mathrm{Na}$ primeira questão “O que é Estatística para você?” observamos que $45(81,8 \%)$ professores dentre o total de 55 professores que a responderam. Ainda em relação ao total de professores, 16 (35,6\%) professores definiram que a Estatística é um conjunto de dados que devem ser coletados, organizados e analisados e que utiliza elementos matemáticos para o seu desenvolvimento. Apresentamos alguns depoimentos que corroboram este posicionamento:

Estatística vai abranger a pesquisa, coleta de dados para determinada questão que utilizará a matemática para os resultados finais. PEM13

Ainda destacamos um grupo de 13 professores (28,9\%) que consideram a Estatística como importante instrumento para um melhor conhecimento do dia a dia. Apresentam-se também depoimentos que indicam esta opinião em relação ao que seja Estatística:

\section{Conteúdos que estão não só na escola, mas no cotidiano das pessoas. PEF10}

Lopes (2008) destaca a necessidade de se lembrar de que as raízes da Estatística estão centradas nas diferentes áreas do conhecimento e esta percepção remete-nos à interdisciplinaridade. O seu ensino deve ocorrer através das experimentações, observações, registros, coletas e análises de dados de modo interdisciplinar, possibilitando aos estudantes o desenvolvimento do sentido crítico, elemento fundamental no exercício de uma cidadania crítica, responsável e participativa.

Outra questão a ser analisada, para a determinação da concepção de como os professores do Ensino Fundamental de escolas públicas e privadas, considera de que forma uma pessoa adquire conhecimentos em Estatística, destaca-se que 25,5\% destes professores acreditam que se adquire este conhecimento no cotidiano, associando a Estatística a situações do dia a dia. Para um melhor entendimento, destacamos as seguintes falas:

Com as vivências do dia a dia, vinculadas às explicações em sala de aula, estruturando o saber mais formal. PEP15

Segundo Corrêa (2012), em relação às experiências profissionais, percepções e concepções dos respondentes em relação ao ensino da Estatística, em sua pesquisa percebeu-se que todos atribuem a Estatística um lugar de relevância, justificando que conhecimentos estatísticos são importantes, pois estão presentes no cotidiano e nas avaliações de larga escala.

Destacam-se também aqueles professores $(19,1 \%)$ que entendem que se adquire conhecimento estatístico por meio de Estudos. Apresentam-se os seguintes testemunhos que indicam este pensamento:

\section{Estudando e buscando conhecimento, começando da base. PEP7}

O processo de aprendizagem subjacente ao estudo implica que o aluno deve se envolver ativamente no processo ensino e aprendizagem, para que não seja um mero receptor de informação durante as aulas. É necessário que o professor conduza o processo de aprendizagem da melhor maneira e com muitos ganhos para a apreensão dos conteúdos a serem aprendidos.

\section{Empenho, exercícios, práticas e explicações. PEE3}

A terceira questão trata-se de quais são os procedimentos metodológicos utilizados por esse grupo de professores durante as suas aulas. Portanto, na análise das suas falas, destacamos cinco grandes categorias. Verifica-se que $19,6 \%$ dos professores demonstraram que o vínculo com o Dia a dia e com o Cotidiano é uma estratégia importante para o processo de ensino-aprendizagem conforme os seguintes relatos:

Gosto muito de trazer atividades concretas como, por exemplo: medidas de capacidade, massa e comprimento é mais fácil e o aluno aprende usando coisas do dia a dia. Trabalho com rótulos e pesquisas, acho muito valioso. PEM14

Na perspectiva de Lopes (2008), é necessário o desenvolvimento de práticas pedagógicas envolvendo situações em que os estudantes realizem atividades considerando seus contextos e que 
estes possam observar e construir os eventos possíveis, por meio de experimentação concreta, de coleta e de organização de dados.

Outra categoria $(17,4 \%)$ em destaque para esta questão refere-se aos professores que trabalham a Estatística a partir de Representações Gráficas relacionadas à realidade dos seus alunos. Indicamos algumas declarações para explicitar melhor estas práticas:

\section{Através de informações de dados, gráficos e material concreto. PEE4}

Segundo Corrêa (2012), destaca que os saberes estatísticos estão ligados a outras disciplinas, sendo expressos em gráficos e tabelas, requerendo conceitos estatísticos para a sua interpretação. Lopes (2010) indicam que se deve incentivar a leitura e a interpretação de gráficos, de tabelas e de medidas publicadas pelos diversos meios de comunicação, a fim de que o aluno saiba posicionar-se de forma crítica diante dessas informações e fornecer-lhes ferramentas para arguir e "desmantelar" informações porventura falaciosas ou mal intencionadas.

A Estatística deve ser aplicada no dia a dia, pois é uma ciência que está a serviço das demais, além de ser um tema interdisciplinar. E considerando estes aspectos, a última pergunta questiona à maneira como os professores incorporam situações do cotidiano em suas aulas de Estatística. Os relatos a seguir demonstram que $28,6 \%$ dos professores incorporam a Estatística em suas aulas através da Prática:

\section{Estabelecendo vínculo com o mundo, por meio de atividades práticas e com materiais didáticos manipulados pelos alunos. PEP2}

Acredita-se que uma forma interessante de adquirir esse conhecimento é por meio da junção de diversos componentes de uma metodologia como a contextualização como cotidiano do aluno, com temas atuais, a prática e a pesquisa, como observa Miguel (2003) que o conhecimento matemático não se consolida como um rol de ideias prontas a serem memorizadas; um processo significativo de ensino de Matemática deve conduzir os alunos à exploração de uma grande variedade de ideias e de estabelecimento de relações entre fatos e conceitos de modo a incorporar os contextos do mundo real, as experiências e o modo natural de envolvimento para o desenvolvimento das noções matemáticas com vistas à aquisição de diferentes formas de percepção da realidade.

Nesta mesma questão, $26,2 \%$ dos professores destacam situações que envolvem pesquisas que utilizam em suas aulas, quais sejam:

Por meio das situações ocasionais (reportagens, informações do governo público, divulgação de dados e pesquisas) ou atividades sequenciadas envolvendo a estatística e probabilidade nas situações problemas. $\boldsymbol{P E F \boldsymbol { B }}$

Onuchic e Allevato (2009) defendem que o problema é ponto de partida para se alcançar o conhecimento e posicionam o professor como guia e o aluno como co-construtor nos processos de ensino-aprendizagem.

Em relação às atitudes dos professores, o instrumento inicial, composto por 35 itens, foi submetido primeiramente a uma Análise Fatorial Exploratória com rotação Varimax, método das componentes principais e autovalores maiores que 1,00 (Kaiser, 1960). Essa análise fatorial foi conduzida sobre uma amostra aleatória com 55 (cinquenta e cinco) questionários respondidos.

Neste estágio do processo de análise, os indicadores submetidos a essa análise foram as condições para a formação da intenção estratégica. Assim, uma verificação do $\mathrm{KMO}=0,659$ e do Teste de Esfericidade de Bartlett $=448,339(\mathrm{p}<0,001)$ permitiu julgar adequada a aplicação da análise fatorial, pois no caso do teste de esfericidade o valor de $\mathrm{p}$ tende a zero e no teste KMO > 0,5; o que permitiu a eliminação de 21 itens.

Desta forma, uma Análise Fatorial Exploratória foi aplicada sobre 18 itens remanescentes. Nesta análise, foi configurada para omitir cargas fatoriais absolutas inferiores a 0,55 (Bowling, 1997), sugerindo a extração de 4 (quatro) fatores que juntos explicam $62,02 \%$ da variação total atribuída aos itens da escala e resultando em uma escala final contendo 14 (quatorze) itens.

Assim, 14 (quatorze) itens foram mantidos na escala (Escala de Atitudes de Professores dos anos iniciais do Ensino Fundamental em relação ao Ensino de Estatística - EAPANE). Uma análise das questões constituintes da escala extraíram 4 (quatro) fatores ou domínios, sugerindo a 
definição dos seguintes constructos ou domínios conceituais: (1) Domínio 1 (CONHECIMENTO CONH): Conhecimento do professor frente a Estatística; (2) Domínio 2 (INSTRUMENTAL INST): Estimulação da instrumentalidade estatística por parte do professor; (3) Domínio 3 (ENSINO - ENS): Adequabilidade das estratégias de ensino adotadas pelo professor; (4) Domínio 4 (CONSCIÊNCIA - CONS): Conscientização dos alunos por parte do professor da utilização da Estatística no cotidiano e da necessidade de conhecimentos matemáticos.

O exame dos dados contidos na Tabela 1., evidenciam valores do Alpha de Cronbach (análise de consistência interna) para os itens ou para os domínios superiores a 0,50 , ponto de corte sugerido por Bowling (1997). A análise do alfa de Cronbach consiste em calcular a correlação que existe entre cada item do teste e o restante dos itens ou o total (escore total) dos itens (Pasquali, 2001).

Tabela 1. Coeficiente de Fidedignidade de Cronbach dos domínios e itens na amostra

\begin{tabular}{lcc}
\hline Itens & Coeficiente de Cronbach & Número de itens \\
\hline ESCALA & 0,809 & 14 \\
CONHECIMENTO (CONH) & 0,899 & 6 \\
INSTRUMENTAL (INST) & 0,883 & 2 \\
ENSINO (ENS) & 0,670 & 4 \\
CONSCIÊNCIA (CONS) & 0,650 & 2 \\
\hline
\end{tabular}

Segundo Field (2009) um valor do $\alpha$ de Cronbach é aceitável se estiver no intervalo de 0,7 a 0,8 e valores substancialmente mais baixos indicam uma escala não confiável. Kline (1999) registra que o valor do $\alpha$ de Cronbach igual a 0,8 é apropriado para testes cognitivos como o teste de inteligência, sendo que para testes de habilidade um ponto de corte de 0,7 é mais adequado. Ele também afirma que quando se tratar de construtos psicológicos, valores abaixo de 0,7 podem ser esperados, por causa da diversidade dos construtos que estão sendo medidos.

Considerando estas referências, há indicação de que as dimensões da escala determinam um instrumento confiável, portanto, mede consistentemente as atitudes positivas dos professores dos anos iniciais do Ensino Fundamental de escolas públicas e privadas de Uberlândia no tocante ao Ensino de Estatística.

\section{CONSIDERAÇÕES FINAIS}

Quando definem o que é Estatística, os professores pensam em coleta, organização e analise de dados, mas ficam na dúvida quanto a ser um método, ou técnica, ou uma ciência ou elementos para tomada de decisão ou parte da matemática aplicada, indicando que é necessário um estudo mais aprofundado dos elementos estatísticos.

Os professores acreditam que a melhor forma de obter o conhecimento estatístico é por meio do estudo da teoria aliada à prática de pesquisa para que os alunos se interessem pela aprendizagem deste conteúdo. Indica-se também que grande parte dos professores pensa que a obtenção deste conhecimento se vincule simplesmente a apresentação de fórmulas e outros nem mesmo expuseram sua opinião podendo indicar a sua não utilização dentre os conteúdos que devem fazer parte da formação de seus alunos.

E quanto à forma como estes professores trabalham os conteúdos estatísticos em sala de aula, alguns deles tomam tabelas e gráficos e associam a situações do cotidiano, mas a maioria diz não saber como apresentar estes conteúdos.

Especificamente, os professores quando perguntados se incorporaram situações do cotidiano às aulas de conteúdos estatísticos, alguns utilizam situações simples do cotidiano do aluno, como dados dos próprios alunos: idade, letra inicial do nome, animais preferidos e até a moeda vigente para elaborar tabelas e gráficos. Da mesma forma que nas questões anteriores, muitos deles também não deixam claro como estes elementos podem ser inseridos em aulas de matemática.

A redução dos itens e que determina os quatro domínios indica aspectos relacionados ao conhecimento do professor em relação ao ensino de Estatística; estimulação da instrumentalidade estatística por parte do professor; adequabilidade das estratégias de ensino adotadas pelo professor; 
e conscientização dos alunos por parte do professor da utilização da Estatística no cotidiano e da necessidade de conhecimentos matemáticos.

Observa-se nestes domínios uma natureza essencialmente cognitiva o que parece indicar que os professores consideram os elementos estatísticos importantes para a formação de seus alunos, mas que não perpassam por elementos afetivos, ou seja, para os professores participantes da pesquisa o ensino de Estatística não é um prazer.

Vislumbra-se que mais docentes passem a compreender e ter uma concepção desse conteúdo com uma visão consciente de tal forma que colaborarem com o preenchimento da lacuna existente de estudos e práticas pedagógicas que contemplem essencialmente da Estatística desde o início do Ensino Fundamental a fim de prolongar aos demais níveis de ensino com sucesso.

\section{REFERÊNCIAS}

Bardin, L. (2009). Análise de conteúdo. Lisboa, Portugal; Edições 70.

Bowling, A. (1997). Measuring health: a review of quality of life measurement scales. Buckmghan Open University Press.

Brito, M.R.F. (1998). Adaptação e Validação de uma escala de atitudes em relação à Matemática. Revista Zetetiké, 6(9), 109-162.

Corrêa, A.A. (2012). Saberes docentes e educação estatística: composições analíticas no Ensino Médio. Educ. Matem. Pesq., São Paulo, 14(1), 67-83.

Field, A. (2009). Descobrindo a estatística usando o SPSS. Tradução de Lorí Viali. Porto Alegre: Artmed.

Kaiser, H.F. (1960). The application of electronic computers to factor analysis. Educational and Psychological Measurement, 20, 141-151.

Kline, P. (1999). The handbook of psychological testing. London: Routledge.

Lopes, C.A.E. (2008). O ensino de estatística e da probabilidade na Educação Básica e a formação de professores. Caderno Cedes, 28(74), 57-73.

Lopes, C. A. E. (2010). Os desafios para Educação Estatística no currículo de matemática. In Lopes, C. A. E. et al. Estudo e reflexões em Educação Estatística. Campinas: Mercado das Letras, p. 47-64.

Miguel, J.C. (2003). O ensino de matemática na perspectiva de formação de conceitos: implicações teóricos-metodológicas. Recuperado de http://www.inf.unioeste.br/ rogerio/Ensino-Matematica-Enfoque-Conceitos.pdf.

Brasil. (1997). Parâmetros curriculares nacionais primeiro e segundo ciclos do Ensino Fundamental: Matemática. Brasília: MEC/SEF.

Brasil. (2004). Guia de livros didáticos: $1^{\mathrm{a}}$ a $4^{\mathrm{a}}$ séries. Brasília: MEC/SEF.

Brasil. (2014). Índice de desenvolvimento da educação básica (Ideb). Brasília: MEC/SEF. Recuperado de http://portal.mec.gov.br.

Moron, C. F., \& Brito, M. R. F. (2001). Atitudes e concepções dos professores da educação infantil em relação à Matemática. In Brito, M. R. F. Psicologia da educação matemática: teoria e pesquisa. Florianópolis: Editora Insular, 263-277.

Oliveira Júnior, A.P., \& Morais, J.F. (2009). Validação da Escala de Atitudes de Professores de Estatística em Relação à Estatística no Ensino Superior no Brasil. Revista Ciência \& Educação, 15(3), 581-591.

Onuchic, L.R., \& Allevato, N.S.G. (2009). Ensinando Matemática na sala de aula através da Resolução de Problemas. Boletim GEPEM, Rio de Janeiro, 55, 1-19.

Pasquali, L. (2001). Técnicas de exame psicológico: manual. São Paulo: Casa do Psicólogo.

Ponte. J. (1992). Concepções dos professores de matemática e processos de formação. in educação e matemática: Temas de Investigação. Lisboa: IIE e Secção de Educação e Matemática da SPCE, 186-239.

Rodrigues, A., Assmar, E., \& Jablonski, B. (2005). Psicologia Social. Petrópolis: Vozes.

Serra, V.V. (2007). Atitudes de professores frente à inclusão educacional: o impacto do suporte e dos valores organizacionais. 2007. 82 f. Dissertação de Mestrado em Educação. Brasília. Faculdade de Educação da Universidade Católica de Brasília.

Zabalza, M.A. (1994). Diários de aula. Contributo para o estudo dos dilemas práticos dos professores. Porto: Porto Editora, Coleção Ciências da Educação. 